\title{
Graft survival and endothelial outcomes after penetrating keratoplasty and Descemet stripping automated endothelial keratoplasty: A systematic review and meta-analysis
}

\author{
KE YANG ${ }^{1}$, YANG ZHAO ${ }^{1}$, HONGSHUANG LU ${ }^{1}$, YUNXIAO ZANG ${ }^{1}$, YU MAO $^{1}$, JIAXU HONG ${ }^{2}$ and YING JIE $^{1}$ \\ ${ }^{1}$ Department of Ophthalmology, Beijing Tongren Eye Center, Beijing Key Laboratory of Ophthalmology and Visual Science, \\ Beijing Tongren Hospital, Capital Medical University, Beijing 100073; ${ }^{2}$ Department of Ophthalmology, \\ Eye \& Ent Hospital, School of Shanghai Medicine, Fudan University, Shanghai 200031, P.R. China
}

Received May 30, 2019; Accepted May 29, 2020

DOI: $10.3892 /$ etm.2020.9010

\begin{abstract}
The present study aimed to compare the outcomes of graft survival, endothelial cell loss and vision improvement between penetrating keratoplasty (PK) and Descemet stripping automated endothelial keratoplasty (DSAEK) for treating corneal endothelium diseases. The PubMed, CENTRAL (Cochrane) and Embase databases were searched for records added until September 20, 2019. The studies considered were two-arm prospective and retrospective studies comparing outcomes of interest between PK and DSAEK. Ultimately, 10 studies were included with a total of 2,634 patients (910 eyes treated with DSAEK; 1,804 eyes treated with PK). Assessment of the summary effect by meta-analysis suggested that, compared with PK treatment, DSAEK was associated with a greater improvement from baseline in best spectacle-corrected visual acuity [difference (diff.) in means of change from baseline $=-0.225,95 \% \mathrm{CI}=-0.341$ to $-0.109, \mathrm{P}<0.001]$ and a reduced loss of endothelial cell density (diff. in means $=-292.05$ cells $/ \mathrm{mm}^{2}, 95 \% \mathrm{CI}=-419.53$ to -146.57 cells $\left./ \mathrm{mm}^{2}, \mathrm{P}<0.001\right)$. Graft survival rates were similar using either PK or DSAEK (odds ratio=1.005, 95\% $\mathrm{CI}=0.329-3.071, \mathrm{P}=0.993)$. The overall results suggested that DSAEK may have an advantage over PK for corneal endothelial dysfunction in terms of the visual acuity outcome. The absence of definite time frames in the comparisons limits the conclusions on endothelial cell loss and graft survival.
\end{abstract}

Correspondence to: Dr Ying Jie, Department of Ophthalmology, Beijing Tongren Eye Center, Beijing Key Laboratory of Ophthalmology and Visual Science, Beijing Tongren Hospital, Capital Medical University, 1 Dongjiaominxiang, Dongcheng, Beijing 100073, P.R. China

E-mail: 183547004@qq.com

Key words: penetrating keratoplasty, Descemet stripping automated endothelial keratoplasty, endothelial cell loss, graft survival, meta-analysis

\section{Introduction}

Corneal endothelial cells do not sufficiently proliferate to enable endothelial regeneration; therefore, diseases of the corneal endothelium, including pseudophakic bullous keratopathy and Fuchs' endothelial dystrophy, require treatment by transplantation of cadaveric donor corneal endothelial cells (1). The two major goals of any corneal transplant procedure are to restore vision and to promote longevity of the donor cornea (1). The surgical treatment for endothelial disease has evolved over time toward endothelial keratoplasty or selective tissue transplantation and away from full-thickness penetrating keratoplasty (PK) (1). Endothelial keratoplasty is associated with less astigmatism, more predictable refractive outcomes, faster visual rehabilitation, a biomechanically more stable globe, as well as reduced frequency of suture infections and rejection (2).

Descemet stripping automated endothelial keratoplasty (DSAEK) has become a common alternative to PK and is becoming the procedure of choice for treating endothelial dysfunction (1-4). In fact, it is already reported to be more popular and adopted more frequently than PK in the US (5), Europe (6), Australia (7) and Asia (8) for the surgical management of corneal endothelial diseases. The primary complication after DSAEK is donor material detachment and dislocation (2). A newer surgical approach is Descemet membrane endothelial keratoplasty (DMEK), which allows for transplantation of less tissue, resulting in improved visual acuity, faster visual rehabilitation and a lower rate of rejection compared with DSAEK and PK $(2,3)$. However, DMEK is the more technically challenging procedure when compared with PK and DSAEK (2).

Several studies have compared visual outcomes, including uncorrected visual acuity, best spectacle-corrected visual acuity (BSCVA), intraoperative and postoperative complications, corneal biomechanical properties, corneal resistance factors and graft survival, following PK and DSAEK (3,4,9-20). The objective of the present study was to compare the outcomes of graft survival, endothelial cell loss and vision improvement between PK and DSAEK in the treatment of corneal endothelial disease. 


\section{Materials and methods}

Search strategy. The study was performed in accordance with the Preferred Reporting Items for Systematic Reviews and Meta-analyses guidelines (21). The PubMed, CENTRAL (Cochrane) and Embase databases were searched for entries added until September 20, 2019. The following keywords were used: (penetrating keratoplasty) AND (Descemet stripping automated endothelial keratoplasty). The search filters applied were as follows: Abstract available; humans. Only two-arm prospective and retrospective studies whose patients underwent PK or DSAEK were considered for inclusion. Studies were required to quantitatively report the outcomes of graft survival, endothelial cell density or visual acuity at baseline and during follow-up. One-arm studies, reviews, letters, comments, editorials, case reports, proceedings and personal communications were excluded.

Initially, the titles and abstracts of the identified studies were screened for eligibility and studies not meeting the inclusion criteria were discarded. The remaining studies underwent full-text review to further determine eligibility. A total of two independent reviewers ( $\mathrm{KY}$ and $\mathrm{YZ}$ ) performed the review and a third reviewer (YM) was consulted to resolve any uncertainties. In addition, the reference lists of the relevant studies were hand-searched to identify further studies that met the inclusion criteria.

Data extraction. The following data were extracted from the included studies: First author's name, study design, study period, indication/diagnosis, incidence of prospective glaucoma, type of keratoplasty, number of eyes or procedures, patient age and gender and length of follow-up. The outcomes of endothelial cell density, graft survival and BSCVA were also extracted. BSCVA was presented in logMAR with lower values representing better visual acuity. Endothelial cell density was reported as the mean \pm standard deviation (SD) $\left(\right.$ cells $/ \mathrm{mm}^{2}$ ) and as \% loss at each time-point of evaluation during follow-up. Data were extracted by two independent reviewers (KY and YZ) and a third author (YM) was consulted, if necessary, to resolve any disagreements.

Quality assessment. The studies included were assessed with the Cochrane Risk of Bias Assessment Tool for Non-Randomized Studies of Interventions (22). The assessment tool includes seven domains: Bias due to confounding, bias in selection of participants into the study, bias in measurement of interventions, bias due to departures from intended interventions, bias due to missing data, bias in measurement of outcomes and bias in selection of the reported result.

Statistical analysis. Patients' baseline characteristics and adverse events are summarized descriptively using the mean $\pm \mathrm{SD}$, mean or median of age with range (min-max). The summary effects of BSCVA and endothelial cell density were calculated as the difference (diff.) in means of change from baseline with $95 \%$ CI between the two groups.

For the categorical outcome of graft survival rate, an effect size of odds ratios (ORs) with 95\% CIs were calculated to compare the rates of graft survival between the two groups. The heterogeneity test among studies was determined using a $\chi^{2}$-based Cochran's $\mathrm{Q}$ statistic and $\mathrm{I}^{2}$. For the $\mathrm{Q}$ statistic, $\mathrm{P}$-values $<0.10$ were considered to indicate statistically significant heterogeneity. For the $\mathrm{I}^{2}$ statistic, heterogeneity was assessed as follows: No heterogeneity $\left(\mathrm{I}^{2}=0-25 \%\right)$, moderate heterogeneity $\left(\mathrm{I}^{2}=25-50 \%\right)$, high heterogeneity $\left(\mathrm{I}^{2}=50-75 \%\right)$ and very high heterogeneity $\left(\mathrm{I}^{2}=75-100 \%\right)$. If the $\mathrm{I}^{2}$ statistic was $>50 \%$ or the $\mathrm{Q}$ statistic value of the $\mathrm{P}$-value was $<0.05$, a random-effects model was used for the meta-analysis. Otherwise, a fixed-effects model was employed. A two-sided P-value of $<0.05$ was considered to indicate statistical significance. A sensitivity analysis was performed using a leave-one-out approach. Publication bias was not assessed, as only $\leq 10$ studies were included in any given meta-analysis (23). All statistical analyses were performed using the statistical software Comprehensive Meta-Analysis, version 2.0 (Biostat).

\section{Results}

Search results and study characteristics. The initial search identified 351 unique studies, 303 of which were removed after the screening of the abstract and title for not meeting the inclusion criteria. Of the 48 studies that underwent full-text review, 38 studies were excluded for not reporting outcomes of interest, being single-arm studies, reviews or having irrelevant study objectives (Fig. 1).

A total of 10 studies were included in the present review and meta-analysis, comprising a total of 2,634 patients, with 910 eyes treated with DSAEK and 1,804 with PK (9-18). Of the 10 studies, 4 had a prospective design and the others were retrospective studies (Table I). The number of patients who received DSAEK surgery across the studies ranged from 12 to 828 and those who were treated with PK ranged from 11 to 1,101 . The proportion of patients who received DSAEK across studies ranged from 13.6 to $61 \%$, whereas that of patients treated by PK ranged from 39 to $86.4 \%$. The patients' mean age was $>60$ years. The indication/diagnosis varied across the studies. The length of follow-up ranged from 1 to 5 years among the studies that reported graft survival and endothelial cell density, and ranged from 3 months to 5 years in the studies that reported on visual acuity outcomes (Table II).

Change of BSCVA from baseline. A total of six studies $(11-15,17)$ had complete data on BSCVA and were included in the pooled analysis. A random-effects model was used for BSCVA, as significant heterogeneity was observed in the data (Q-value $\left.=13.90, \mathrm{P}=0.016, \mathrm{I}^{2}=64.04 \%\right)$. The summary effect indicated that the DSAEK group had a greater BSCVA improvement from baseline as compared with the PK group (diff. in means of change from baseline $=-0.225,95 \% \mathrm{CI}=-0.341$ to -0.109 , P<0.001; Fig. 2).

Graft survival rate. A total of four studies $(9,10,15,18)$ had complete data on the rate of graft survival and were included in the analysis. A random-effects model was applied due to the high degree of heterogeneity in the data $(\mathrm{Q}-\mathrm{value}=27.37$, $\mathrm{P}<0.001, \mathrm{I}^{2}=89.04 \%$ ). The summary effect indicated that the rate of graft survival was similar between the PK and DSAEK groups (OR=1.005, 95\% CI=0.329-3.071, $\mathrm{P}=0.993$; Fig. 3). 


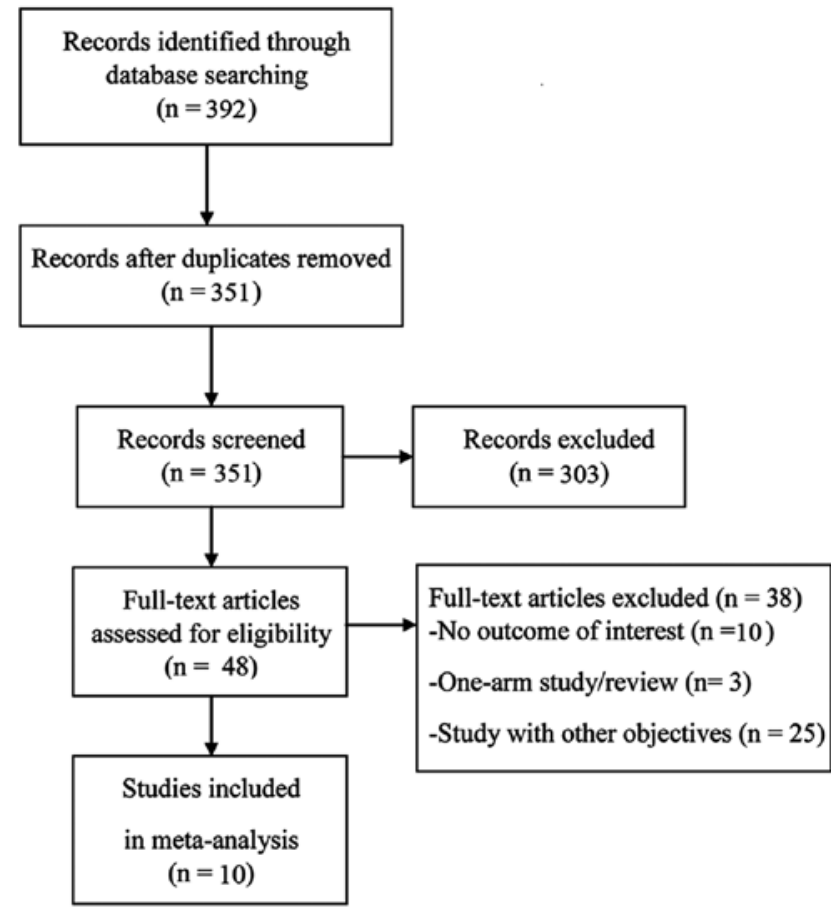

Figure 1. Flow chart for study selection.

Changes in endothelial cell density. A total of five studies $(9,10,14-16)$ had post-operative data regarding endothelial cell density and were included in the analysis. A random-effects model was applied due to very high heterogeneity in the data (Q-value $\left.=51.90 ; \mathrm{P}<0.001 ; \mathrm{I}^{2}=92.29 \%\right)$. The summary effect revealed that the DSAEK group had less loss of endothelial cell density than the PK group (diff. in means $=-292.05$ cells $/ \mathrm{mm}^{2}, 95 \%$ CI $=-419.53$ to -146.57 cells $/ \mathrm{mm}^{2}$, $\mathrm{P}<0.001$; Fig. 4).

Adverse events. Table III presents the adverse events in patients who received DSAEK and PK, including intraocular pressure elevation (13.3-17.2 vs. 9.1-36.8\%), graft detachment/dislocation (0-13.3 vs. $6.3 \%$ ), anterior synechiae ( 0 vs. $1.1 \%$ ), wound dehiscence ( 0 vs. $2.7-4.6 \%$ ) and secondary glaucoma (6.7 vs. $6.3 \%$ ), respectively. However, quantitative data synthesis was not performed due to the insufficient data reported (Table III).

Sensitivity analysis. Sensitivity analysis was performed using the leave-one-out approach, in which the meta-analyses were performed after each study was removed in turn (Fig. S1). The direction and magnitude of combined estimates did not vary markedly with the removal of any single study, indicating that the results were robust and no single study overly influenced the results. However, the removal of Pedersen et al (2015) (18) produced a significant result regarding graft survival rate.

Quality assessment. The results of the quality assessment of the included studies are presented in Fig. 5. Overall, the studies were of fair quality and most studies had a low risk of bias in the selection of participants into the study, bias in measurement of interventions, bias in measurement of outcomes, bias due to departures from intended interventions and bias in selection of the reported result. However, with regard to bias due to confounding, one study had high risk of bias and about half of the included studies had intermediate risk of bias. The risk of bias of most concern was bias due to missing data, with high risk determined in four studies (Fig. 5).

\section{Discussion}

Diseases of the corneal endothelium require treatment by transplantation of corneal endothelial cells (2). The present review and meta-analysis was designed to compare outcomes following PK and DSAEK surgeries. The results indicated that DSAEK was associated with a greater improvement from baseline in BSCVA and a reduced loss of endothelial cell density during follow-up compared with PK $(\mathrm{P}<0.001)$. The rates of graft survival were similar between the two procedures. However, the exclusion of the study by Pedersen et al (18) led to a significant benefit from DSAEK over PK.

A prior meta-analysis performed by Akanda et al (20) in 2015 compared the major surgical outcomes following PK and lamellar procedures. The analysis included 22 studies, three of which were randomized controlled trials and the others were cohort studies. Lamellar procedures included deep anterior lamellar keratoplasty and pre-Descemet anterior lamellar keratoplasty, and were referred to as 'anterior lamellar procedures'. They also included Descemet stripping endothelial keratoplasty and DMEK and were referred to as 'posterior lamellar keratoplasty'. Akanda et al (20) determined that PK was associated with a greater risk of rejection $(\mathrm{OR}=3.56 ; 95 \%$ $\mathrm{CI}=1.76-7.20)$ and graft failure (OR=2.85; 95\% $\mathrm{CI}=0.84-9.66)$ than anterior lamellar procedures. Compared with posterior lamellar procedures, PK also had a greater likelihood for rejection $(\mathrm{OR}=1.52 ; 95 \% \mathrm{CI}=1.00-2.32)$ and outright failure $(\mathrm{OR}=2.09 ; 95 \% \mathrm{CI}=0.57-7.59)$. In addition, $\mathrm{PK}$ resulted in a longer follow-up time for full transplants than the lamellar procedures.

The pooled graft survival rate in the present review did not show significant difference between PK and DSAEK, which was inconsistent with the result in the meta-analysis by Akanda et al (20). However, this was mostly due to the study by Pedersen et al (18). In the present review, of the four studies included in the meta-analysis for graft survival, only the findings of Pedersen et al (18) favored the PK group, possibly reflecting the fact that the investigators focused on secondary endothelial dysfunction. Removal of Pedersen et al (18) from the pooled analysis resulted in a reduction in the heterogeneity of the data (Q-value $\left.=1.73, \mathrm{P}=0.421, \mathrm{I}^{2}=0 \%\right)$ and the pooled analysis indicated that DSAEK resulted in higher graft survival compared with $\mathrm{PK}(\mathrm{OR}=1.817,95 \% \mathrm{CI}=1.360-2.426, \mathrm{P}<0.001)$, which was comparable to the result of Akanda et al (20). These results suggest that PK and DSAEK treatments may have different effects on primary and secondary endothelial dysfunction.

The present systematic review and meta-analysis had several limitations that should be considered when interpreting the results. The meta-analyses included only a small number of studies and none of the included studies was a randomized controlled trial. The underlying disease/cause for the requirement 


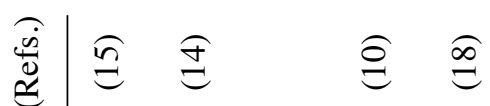

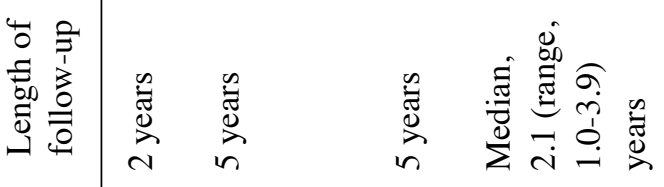

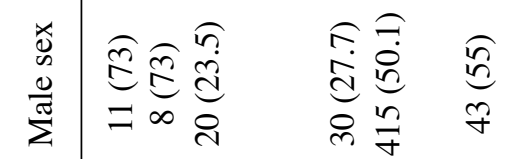

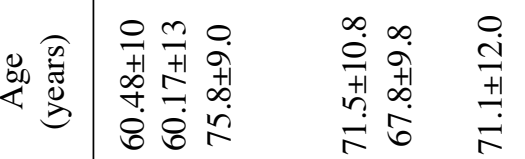

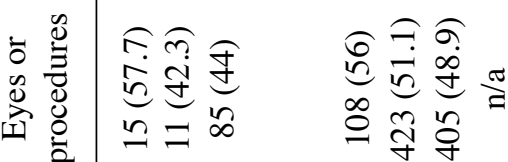

$\Rightarrow$ व

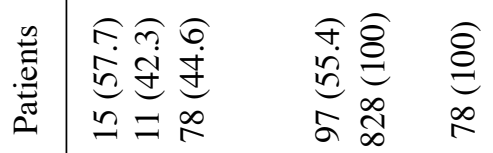

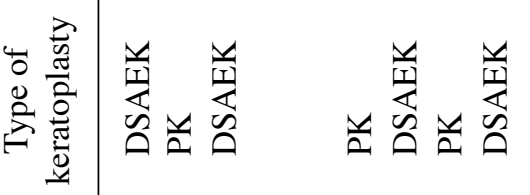

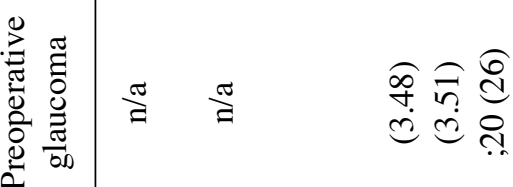

0
0
0
0
0
0
0
0
0
0

牙

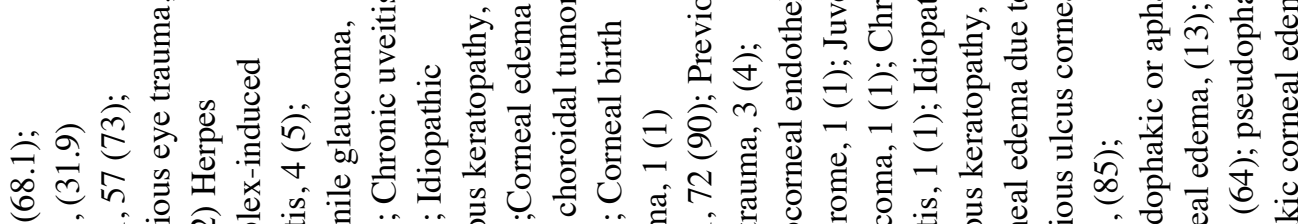

$\underset{\infty}{\stackrel{\delta}{\varnothing}}$

$\frac{4}{2}$

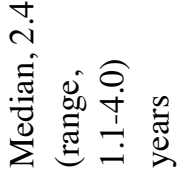

$\stackrel{6}{=}$

$\widehat{\vec{c}}$

子

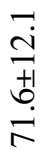

$\stackrel{乛}{\nexists}$

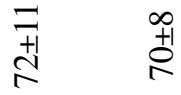

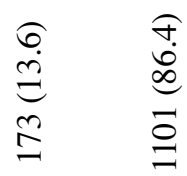

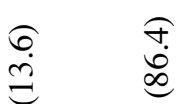

$\stackrel{0}{=} \quad \stackrel{0}{=}$

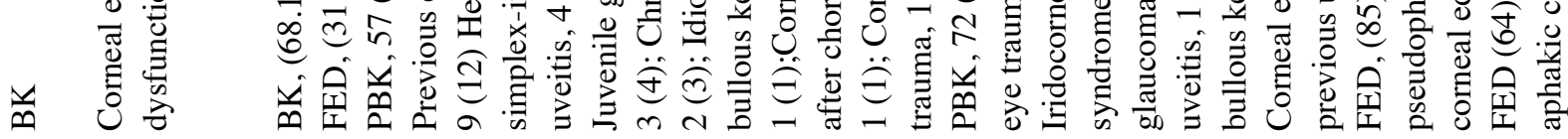

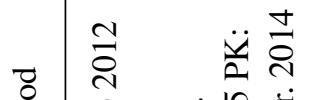

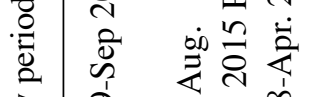

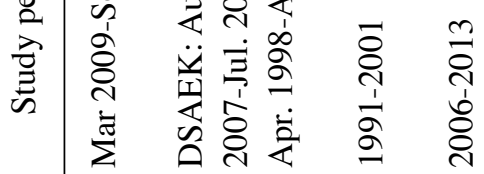

$\stackrel{2}{3}$

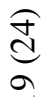

$\stackrel{\pi}{\Xi}$

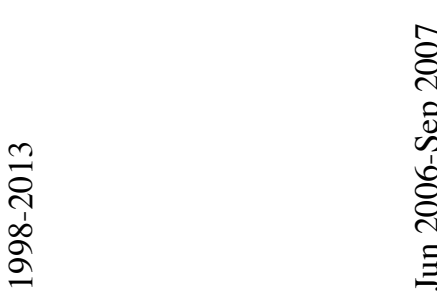

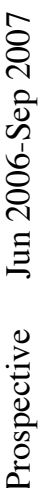

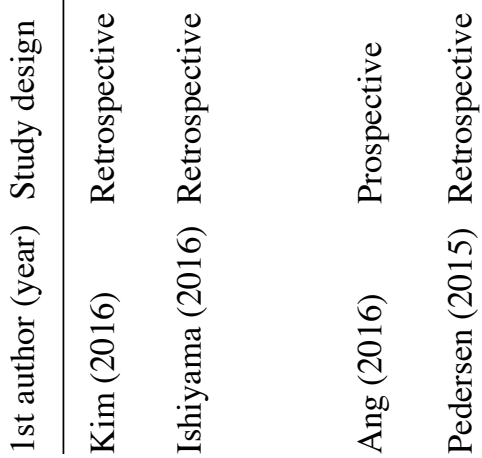

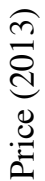




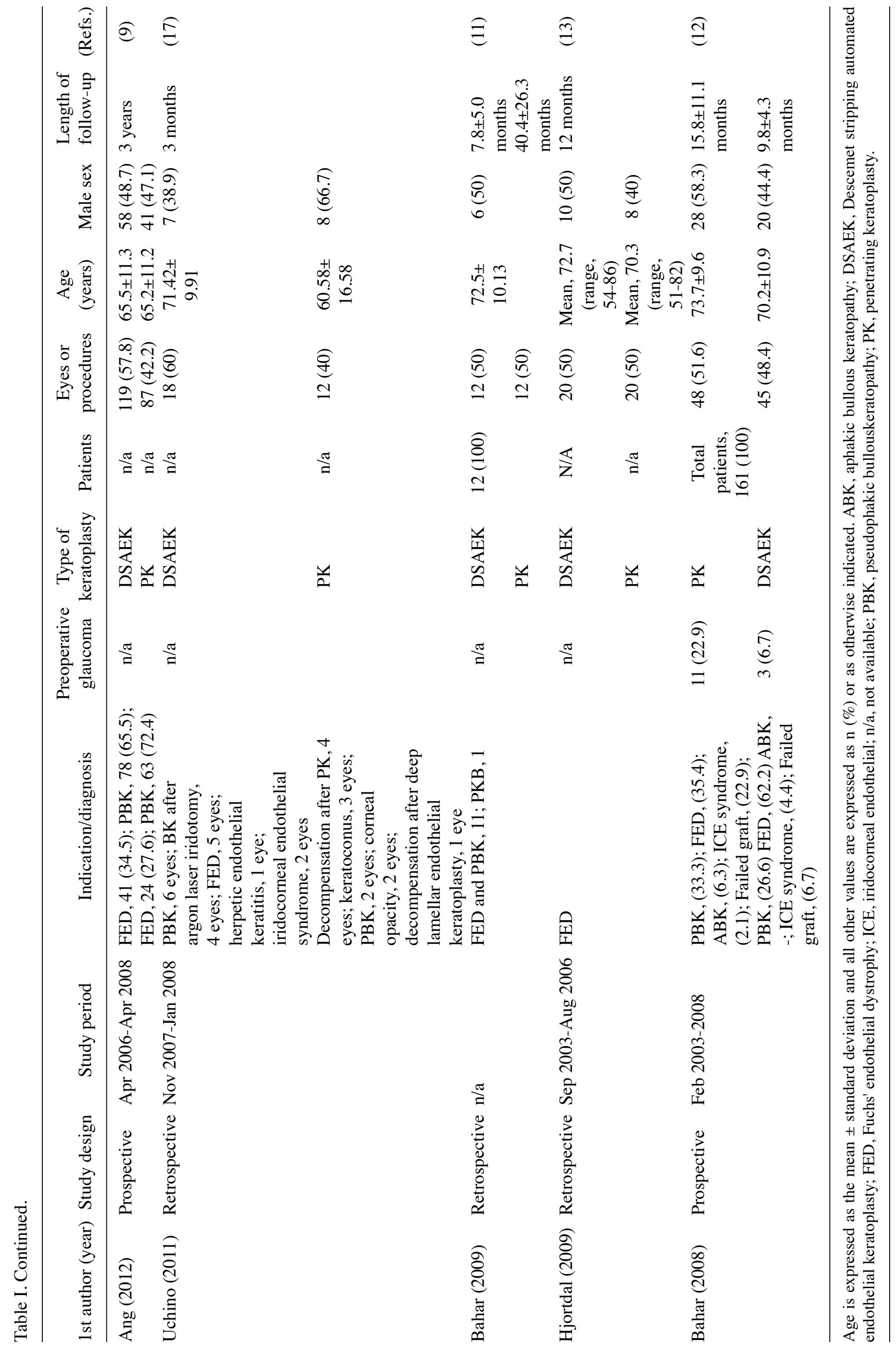




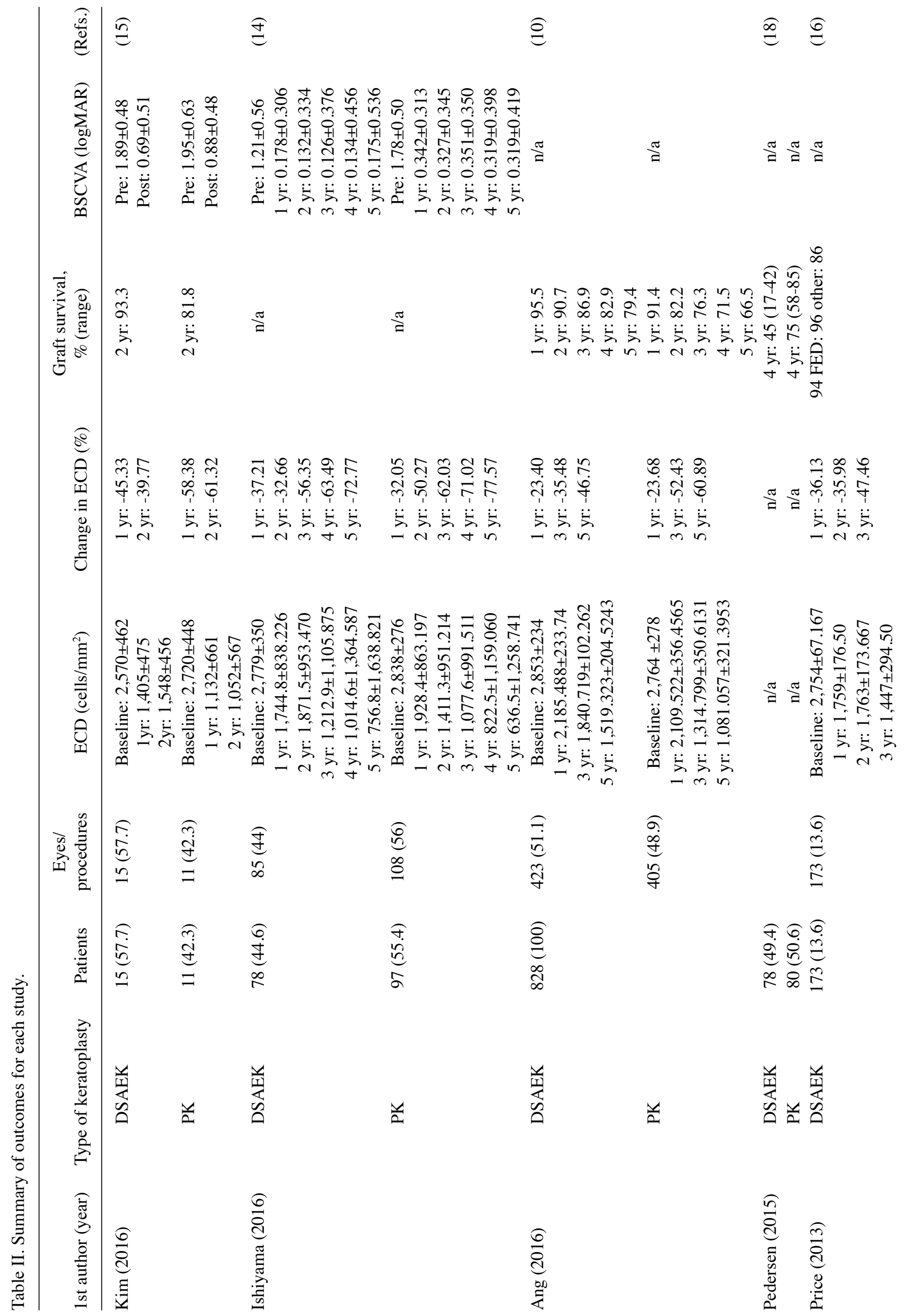




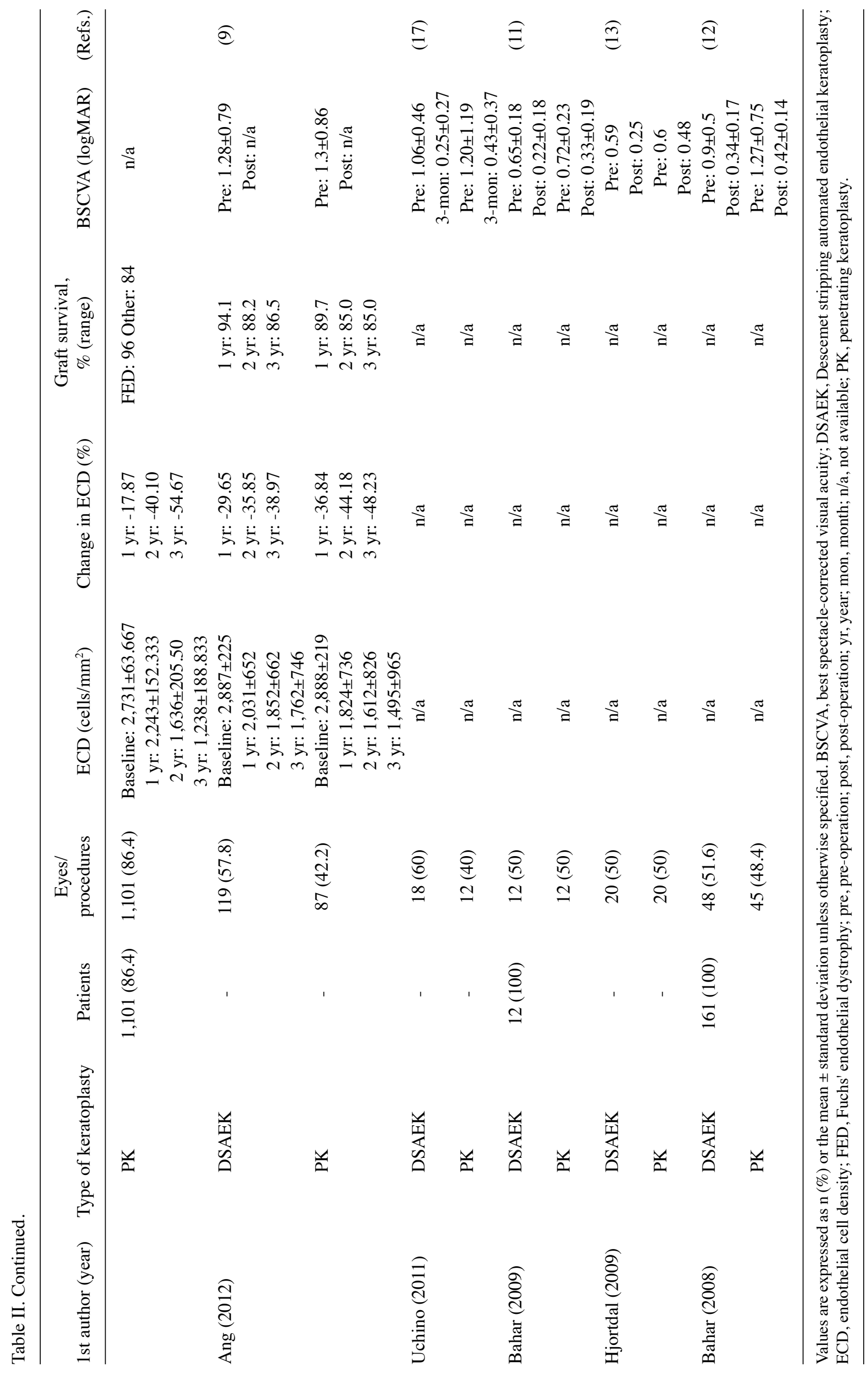




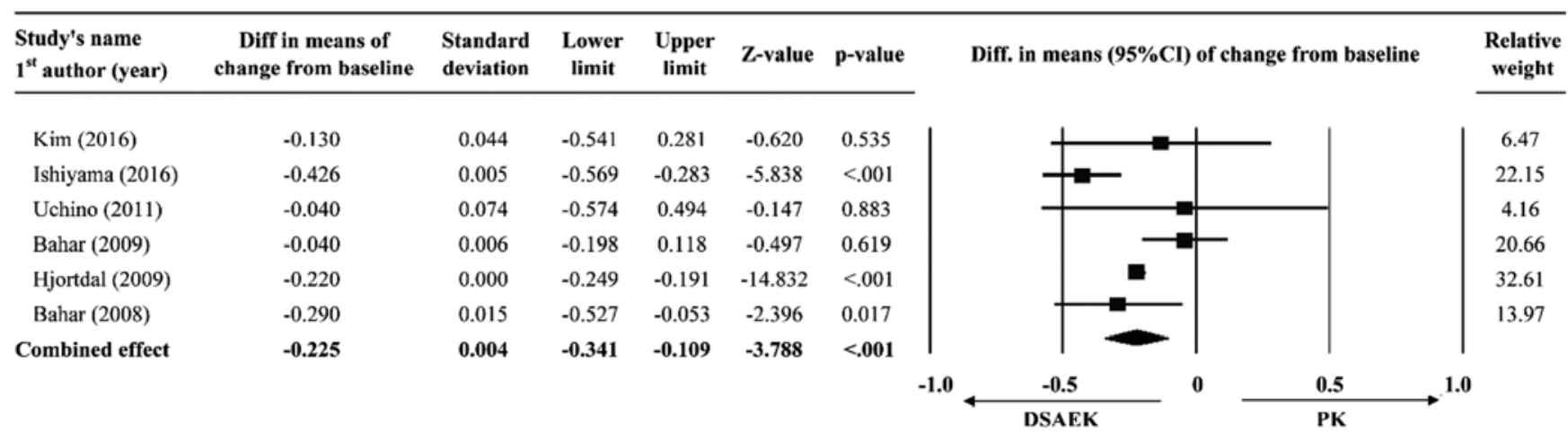

Heterogeneity test: $\mathrm{Q}$-value $=13.90$, P-value $=0.016$, I-squared $=64.04 \%$

Figure 2. Meta-analysis of best spectacle-corrected visual acuity between the PK and DSAEK groups. Diff, difference; PK, penetrating keratoplasty; DSAEK, Descemet stripping automated endothelial keratoplasty.

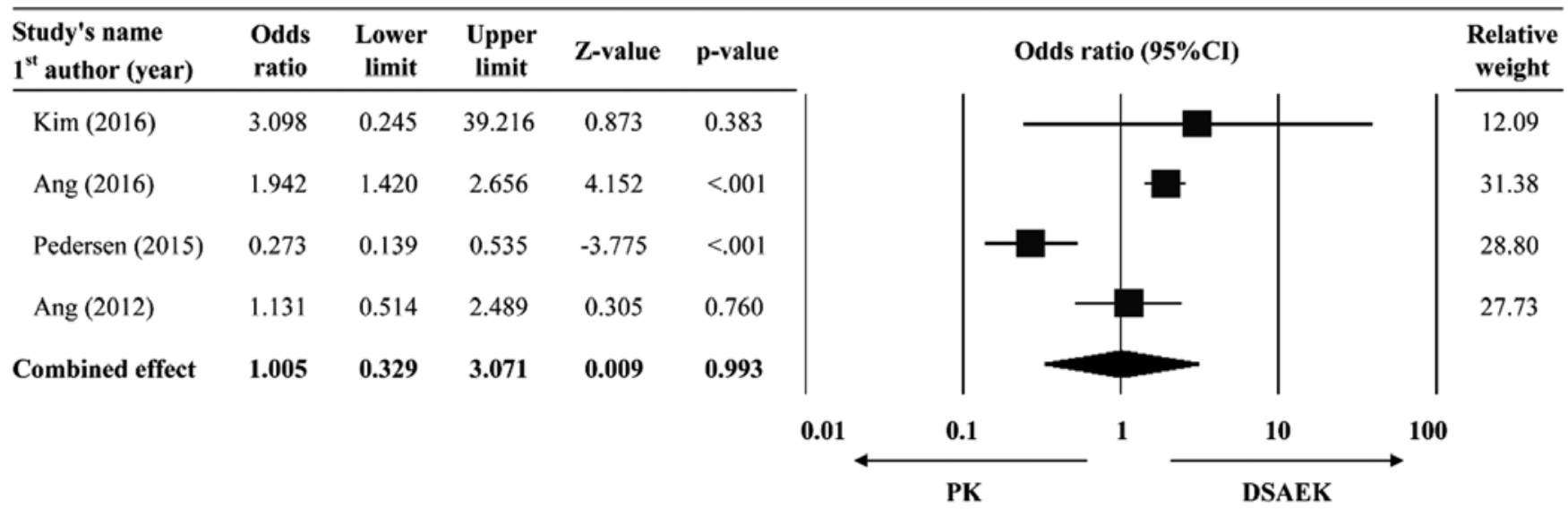

Heterogeneity test: Q-value=27.37, P-value $<.001, \mathrm{I}$-squared $=89.04 \%$

Figure 3. Meta-analysis of the graft survival rate between the PK and DSAEK groups. PK, penetrating keratoplasty; DSAEK, Descemet stripping automated endothelial keratoplasty.

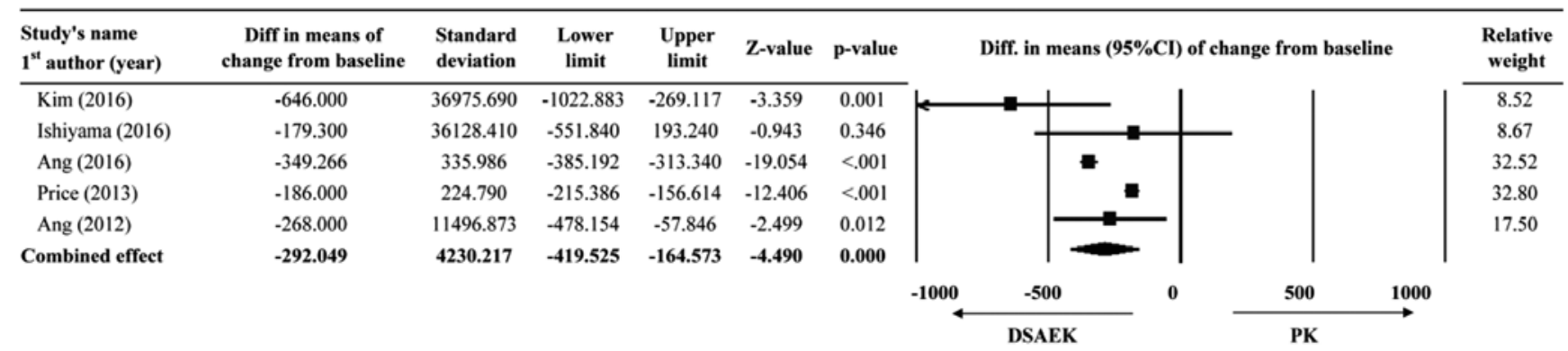

Heterogeneity test: Q-value=51.898, P-value $<.001$, l-squared=92.293\%

Figure 4. Meta-analysis of endothelial cell density compared between the PK and DSAEK groups. Diff, difference; PK, penetrating keratoplasty; DSAEK, Descemet stripping automated endothelial keratoplasty.

of corneal transplant varied across studies, which may have confounded the results, and in addition, the meta-analysis did not assess any potential differences in the incidence of adverse events between the surgical approaches. In addition, the range of surgical indications was broad (e.g., Fuchs' endothelial disease and bullous keratopathy, post-keratoplasty endothelial failure, iridocorneal endothelial syndrome and herpetic keratitis), and each of them has a different prognosis, leading to high complexity in this comparison. Furthermore, the outcomes between the two procedures were not compared, e.g., by categorizing the patients 
Table III. Summary of adverse events among studies.

\begin{tabular}{|c|c|c|c|c|c|c|c|}
\hline 1st author (year) & $\begin{array}{c}\text { Type of } \\
\text { keratoplasty }\end{array}$ & $\begin{array}{c}\text { IOP } \\
\text { elevation }\end{array}$ & $\begin{array}{l}\text { Graft detachment/ } \\
\text { dislocation }\end{array}$ & $\begin{array}{l}\text { Anterior } \\
\text { synechiae }\end{array}$ & $\begin{array}{c}\text { Wound } \\
\text { dehiscence }\end{array}$ & $\begin{array}{l}\text { Secondary } \\
\text { glaucoma }\end{array}$ & (Refs.) \\
\hline \multirow[t]{2}{*}{ Kim (2016) } & DSAEK & $2(13.3)$ & $2(13.3)$ & $\mathrm{n} / \mathrm{a}$ & $\mathrm{n} / \mathrm{a}$ & $\mathrm{n} / \mathrm{a}$ & \multirow[t]{2}{*}{$(15)$} \\
\hline & $\mathrm{PK}$ & $1(9.1)$ & $\mathrm{n} / \mathrm{a}$ & $\mathrm{n} / \mathrm{a}$ & $\mathrm{n} / \mathrm{a}$ & $\mathrm{n} / \mathrm{a}$ & \\
\hline \multirow[t]{2}{*}{ Ishiyama (2016) } & DSAEK & $\mathrm{n} / \mathrm{a}$ & $5(5.9)$ & $\mathrm{n} / \mathrm{a}$ & $\mathrm{n} / \mathrm{a}$ & $\mathrm{n} / \mathrm{a}$ & \multirow[t]{2}{*}{ (14) } \\
\hline & PK & $\mathrm{n} / \mathrm{a}$ & $\mathrm{n} / \mathrm{a}$ & $\mathrm{n} / \mathrm{a}$ & $3(2.7)$ & $\mathrm{n} / \mathrm{a}$ & \\
\hline \multirow[t]{2}{*}{ Ang (2012) } & DSAEK & $20(17.2)$ & $3(2.6)$ & $0(0)$ & $0(0)$ & $\mathrm{n} / \mathrm{a}$ & \multirow[t]{2}{*}{ (9) } \\
\hline & PK & $32(36.8)$ & $\mathrm{n} / \mathrm{a}$ & $1(1.1)$ & $4(4.6)$ & $\mathrm{n} / \mathrm{a}$ & \\
\hline \multirow[t]{2}{*}{ Bahar (2008) } & DSAEK & $\mathrm{n} / \mathrm{a}$ & $0(0)$ & $\mathrm{n} / \mathrm{a}$ & $\mathrm{n} / \mathrm{a}$ & $3(6.7)$ & \multirow[t]{2}{*}{ (12) } \\
\hline & $\mathrm{PK}$ & $\mathrm{n} / \mathrm{a}$ & $3(6.3)$ & $\mathrm{n} / \mathrm{a}$ & $\mathrm{n} / \mathrm{a}$ & $3(6.3)$ & \\
\hline
\end{tabular}

Values are expressed as n (\%). DSAEK, Descemet stripping automated endothelial keratoplasty; n/a, not available; PK, penetrating keratoplasty; IOP, intraocular pressure.
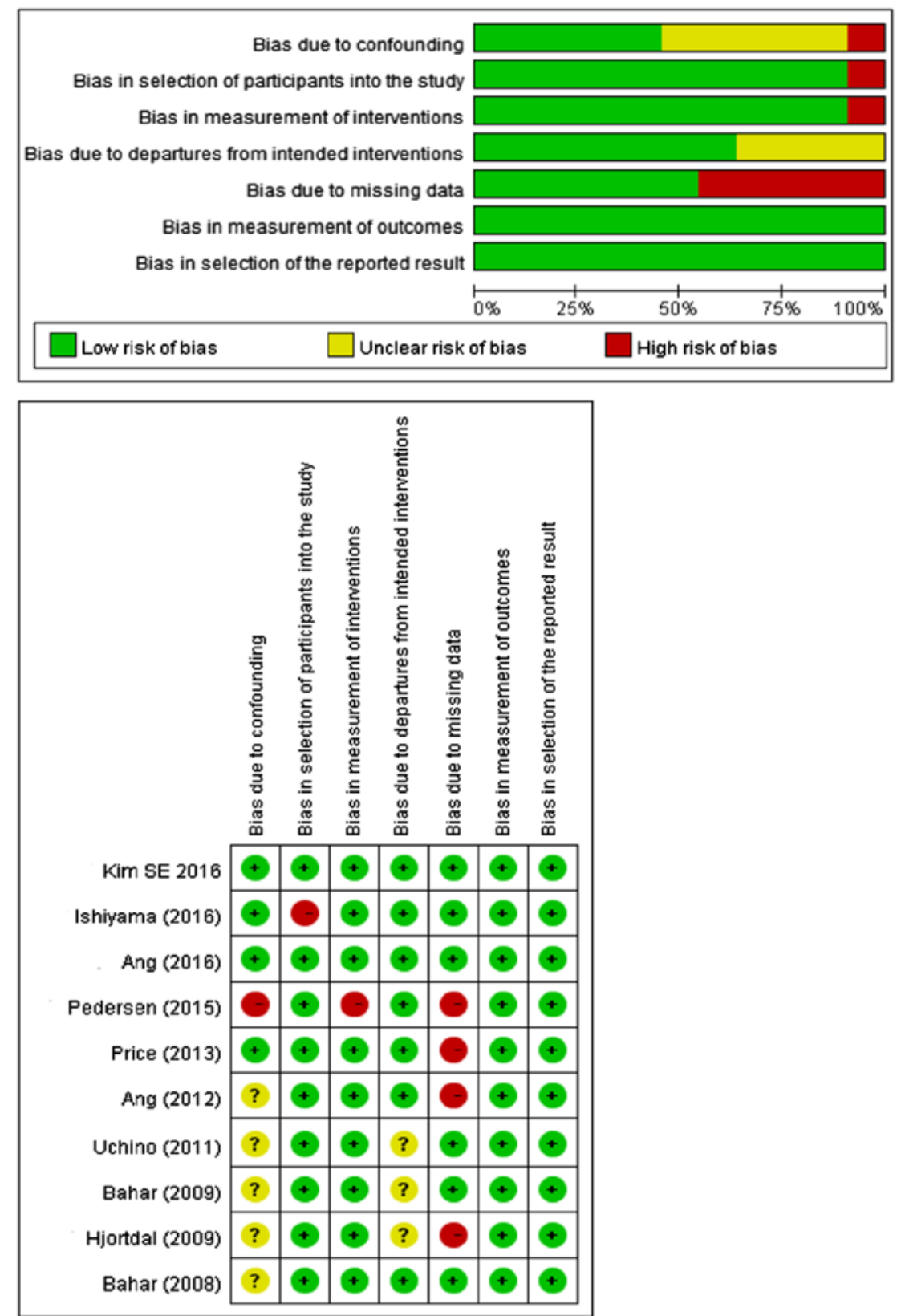

Figure 5. Quality assessment (A) Overall summary of bias of the included studies. (B) Risk of bias for each included study. 
into different surgical indications. In addition, graft survival and endothelial density changes from baseline to the last follow-up were assessed in the present analysis, which were not uniform across the studies included. However, it is known that these outcomes are time-sensitive and it is possible that the results may have differed depending upon the time-points chosen. For instance, in the study by Ishiyama et al (14) from 2016, corneal endothelial cell density was lower for DSAEK at 6 months post-surgery but was significantly higher at 2 years. However, at three years, the endothelial cell density was similar between the groups. Another study by Price et al (2016) (24) indicated that the rate of cell loss over time differed between DSAEK and PK; specifically, at 3-5 years, cell loss was less with DSAEK but at the 10-year follow-up, no significant differences were identified. Accordingly, well-designed studies with clear time frames for evaluating these outcomes are warranted. Quantitative data synthesis on adverse events was not performed due to the insufficient data reported, precluding definite conclusions regarding adverse events.

In summary, the present review and meta-analysis suggested that DSAEK results in a significantly greater improvement in BSCVA compared with PK. Overall, the results suggested that DSAEK may be a better surgical treatment option than $\mathrm{PK}$ in terms of visual acuity outcome for corneal endothelial dysfunction.

\section{Acknowledgements}

Not applicable.

\section{Funding}

No funding was received.

\section{Availability of data and materials}

All data generated or analyzed during this study are included in this published article.

\section{Authors' contributions}

$\mathrm{KY}, \mathrm{YZ}$, HSL and YXZ conceived the review. KY and YJ conducted the literature search. Titles, abstracts and articles were screened by KY, YZ, HSL and YXZ. Data extraction was performed by KY, YZ and YM. JXH performed the statistical analysis. KY, YZ, HSL and YXZ drafted the manuscript. YJ critically revised the manuscript. All authors read and approved the final manuscript.

\section{Ethics approval and consent to participate}

Not applicable.

\section{Patient consent for publication}

Not applicable.

\section{Competing interests}

The authors declare that they have no competing interests.

\section{References}

1. Patel SV: Graft survival and endothelial outcomes in the new era of endothelial keratoplasty. Exp Eye Res 95: 40-47, 2012.

2. Ple-Plakon PA and Shtein RM: Trends in corneal transplantation: Indications and techniques. Curr Opin Ophthalmol 25: 300-305, 2014.

3. Price MO and Price FW Jr: Endothelial keratoplasty-a review. Clin Exp Ophthalmol 38: 128-140, 2010.

4. Lee WB, Jacobs DS, Musch DC, Kaufman SC, Reinhart WJ and Shtein RM: Descemet's stripping endothelial keratoplasty: Safety and outcomes: A report by the American Academy of Ophthalmology. Ophthalmology 116: 1818-1830, 2009.

5. Park CY, Lee JK, Gore PK, Lim CY and Chuck RS: Keratoplasty in the United States: A 10-year review from 2005 through 2014. Opthalmology 122: 2432-2442, 2015.

6. Dickman MM, Peeters JM, vonden Biggelaur FJ, Ambergen TA, van Dongen MC, Kruit PJ and Nuijts RM: Changing practice patterns and long-term outcomes of endothelialversus penetrating keratoplasty: A prospective dutch registry study. Am J Opthalmol 170: 133-142, 2016.

7. Williams KKM, Galettis R, Jones V, Mills R and Coster D: The Australian Corneal Graft Resitry-2015 Report. Available at: https://dspace.flinders.edu.au/scmhai/handle/2328/35402. Published 2015. Accessed Feb 16, 2020.

8. Tan D, Ang M, Arundhati A and Khor WB: Development of selectivelamellar keratoplasty within an Asian corneal transplant program: The Singapore Corneal Transplant Study. Trans Am Opthalmol Soc 113: T10, 2015.

9. Ang M, Mehta JS, Lim F, Bose S, Htoon HM and Tan D: Endothelial cell loss and graft survival after Descemet's stripping automated endothelial keratoplasty and penetrating keratoplasty. Ophthalmology 119: 2239-2244, 2012.

10. Ang M, Soh Y, Htoon HM, Mehta JS and Tan D: Five-year graft survival comparing descemet stripping automated endothelial keratoplasty and penetrating keratoplasty. Ophthalmology 123 : 1646-1652, 2016.

11. Bahar I, Kaiserman I, Levinger E, Sansanayudh W, Slomovic AR and Rootman DS: Retrospective contralateral study comparing descemet stripping automated endothelial keratoplasty with penetrating keratoplasty. Cornea 28: 485-488, 2009.

12. Bahar I, Kaiserman I, McAllum P, Slomovic A and Rootman D: Comparison of posterior lamellar keratoplasty techniques to penetrating keratoplasty. Ophthalmology 115: 1525-1533, 2008.

13. Hjortdal $\mathbf{J}$ and Ehlers $\mathrm{N}$ : Descemet's stripping automated endothelial keratoplasty and penetrating keratoplasty for Fuchs' endothelial dystrophy. Acta Ophthalmol 87: 310-314, 2009.

14. Ishiyama S, Mori Y, Nejima R, Tokudome T, Shimmura S, Miyata K and Amano S: Comparison of long-term outcomes of visual function and endothelial cell survival after descemet stripping automated endothelial keratoplasty and penetrating keratoplasty using mixed-effects models. Cornea 35: 1526-1532, 2016.

15. Kim SE, Lim SA, Byun YS and Joo CK: Comparison of long-term clinical outcomes between Descemet's stripping automated endothelial keratoplasty and penetrating keratoplasty in patients with bullous keratopathy. Korean J Ophthalmol 30: 443-450, 2016.

16. Price MO, Gorovoy M, Price FW Jr, Benetz BA, Menegay HJ and Lass JH: Descemet's stripping automated endothelial keratoplasty: Three-year graft and endothelial cell survival compared with penetrating keratoplasty. Ophthalmology 120: 246-251, 2013.

17. Uchino Y, Shimmura S, Yamaguchi T, Kawakita T, Matsumoto Y, Negishi K and Tsubota K: Comparison of corneal thickness and haze in DSAEK and penetrating keratoplasty. Cornea 30: 287-290, 2011.

18. Pedersen IB, Ivarsen A and Hjortdal J: Graft rejection and failure following endothelial keratoplasty (DSAEK) and penetrating keratoplasty for secondary endothelial failure. Acta Ophthalmol 93: 172-177, 2015.

19. Nanavaty MA, Wang $X$ and Shortt AJ: Endothelial keratoplasty versus penetrating keratoplasty for Fuchs endothelial dystrophy. Cochrane Database Syst Rev: Cd008420, 2014.

20. Akanda ZZ, Naeem A, Russell E, Belrose J, Si FF and Hodge WG: Graft Rejection rate and graft failure rate of penetrating keratoplasty (PKP) vs lamellar procedures: A systematic review. PLoS One 10: e0119934, 2015. 
21. Moher D, Liberati A, Tetzlaff J, Altman DG and Group P: Preferred reporting items for systematic reviews and meta-analyses: The PRISMA statement. PLoS Med 6: e1000097, 2009

22. Sterne JA, Hernán MA, Reeves BC, Savović J, Berkman ND, Viswanathan M, Henry D, Altman DG, Ansari MT, Boutron I, et al: ROBINS-I: A tool for assessing risk of bias in non-randomized studies of interventions. BMJ 355: i4919, 2016.

23. Sterne JA, Sutton AJ, Ioannidis JP, Terrin N, Jones DR, Lau J, Carpenter J, Rücker G, Harbord RM, Schmid CH, et al: Recommendations for examining and interpreting funnel plot asymmetry in meta-analyses of randomised controlled trials. BMJ 343: d4002, 2011.
24. Price MO, Calhoun P, Kollman C, Price FW Jr and Lass JH: Descemet stripping endothelial keratoplasty: Ten-year endothelial cell loss compared with penetrating keratoplasty. Opthalmology 123: 1421-1427, 2016.

(i) (2) $\odot$ This work is licensed under a Creative Commons Attribution-NonCommercial-NoDerivatives 4.0 International (CC BY-NC-ND 4.0) License. 